DOI: $10.5007 / 2175-7941.2013 v 30 n 1 p 131$

UM OBJETO-MODELO DIDÁTICO DO MOVIMENTO APARENTE DO SOL EM RELAÇÃO AO FUNDO DE ESTRELAS ${ }^{+*}$

\title{
Francisco Catelli
}

Odilon Giovannini

Departamento de Física e Química - Universidade de Caxias do Sul Caxias do Sul - RS

Fernando Siqueira da Silva

Universidade Federal do Pampa

São Borja - RS

\section{Resumo}

"Por que o Sol nunca passa pela constelação de Órion?" A resposta a essa pergunta, feita por um aluno, inicia com uma revisão da literatura sobre modelos, em especial aqueles relacionados aos objetos-modelo didáticos. A pergunta é respondida, então, inicialmente, usando um mapa do céu, o qual é, em seguida, transformado em um cilindro, e este, por sua vez, é montado em um dispositivo didático de modo a materializar o movimento aparente da abóbada celeste, em uma latitude escolhida, constituindo-se, assim, em um verdadeiro "mini planetário". Contudo, para chegar a um nível de resposta que inclua conceitos como o da vertical do lugar, a invariância da orientação do eixo de rotação da Terra, o equador celeste e a eclíptica, fazem-se necessários outros modelos. Por fim, conclui-se que não é apenas um, mas sim um conjunto articulado de modelos que pode levar a uma resposta aceitável à questão proposta.

\footnotetext{
A didactic model-object of the Sun apparent movement in relation to the background stars

* Recebido: maio de 2012. Aceito: outubro de 2012.
}

Cad. Bras. Ens. Fís., v. 30, n. 1: p. 131-155, abr. 2013. 
Palavras-chave: Objeto-modelo didático. Movimento aparente do Sol. Ensino de Astronomia

\begin{abstract}
"Why does not the Sun move through the Orion's constellation?" The answer to this student's question begins with a literature review of models, especially those referring to didactic modelobjects. Initially, the question is answered using a sky map, which is then transformed into a cylinder, and finally it is assembled into a didactic device to materialize the apparent movement of the celestial vault in a choosen latitude; in fact, this device works like a small-size planetarium. However, in order to reach a level of response that includes concepts such as the vertical of the observer's place, the orientation invariance of the Earth rotation axis vector, the celestial equator and the ecliptic, other models are needed. Finally, we conclude that there is not only one, but a linked set of didactic models that can lead to an acceptable answer to the original question.
\end{abstract}

Keywords: Didactic model-object. Sun apparent movement. Astronomy teaching.

\title{
I. Introdução
}

"Por que o Sol não passa pela constelação de Órion?"

Essa questão foi proposta por um aluno após o professor ter mencionado que uma das três Marias (estrela da constelação de Órion) se move no céu praticamente sobre o equador celeste ${ }^{1}$. Outra maneira equivalente de formular a pergunta seria a seguinte: por que não existe o signo de Órion?

\footnotetext{
${ }^{1}$ A linha do equador celeste é o círculo resultante da intersecção da esfera celeste com o plano perpendicular ao eixo de rotação da Terra, que contém o centro desta. O plano que contém o equador celeste, portanto, contém também o equador terrestre.
} 
A questão surgiu no contexto de uma oficina que tratava da construção de um objeto-modelo didático ${ }^{2}$ do movimento aparente do Sol (SILVA; CATELLI; GIOVANINNI, 2010). Esse objeto-modelo didático ou modelo didático consiste basicamente de uma faixa cilíndrica transparente, que representa a abóbada celeste, na qual estão impressas as trajetórias aparentes do Sol ao longo do ano; a inclinação do eixo desse cilindro está de acordo com a latitude do local, e permite prever o movimento aparente do Sol (MAS) em qualquer época do ano, em qualquer local do planeta. Trata-se de um modelo simples de construir e de usar; entretanto, sua compreensão profunda está associada a um segundo modelo didático, que configura a invariância da orientação do eixo de rotação da Terra. A questão acima, que é o objeto deste trabalho, não pode ser respondida no contexto do modelo do MAS, desenvolvido no trabalho citado acima.

Seria possível, por exemplo, consultar cartas celestes informatizadas que permitem ajustar a data na qual o fundo de estrelas e a posição do Sol são apresentados: mesmo recuando ou avançando muitos anos, nunca veremos o Sol na constelação de Órion. Então, a resposta seria “não". Mas essa não é, de modo algum, uma resposta que seja de construção trivial. Este artigo conduz a uma cadeia de modelos que levam à resposta a essa e a outras perguntas, possíveis de serem elaboradas (e respondidas!).

\section{Modelos, objetos-modelo didáticos, modelos na Astronomia}

O que é um modelo? O sentido atribuído a essa palavra se tornou tão vasto que é praticamente impossível chegar a uma definição universal (Le MOIGNE, 1987, p. 1-6). Em uma perspectiva epistemológica, modelos podem ser considerados estruturas concretas ou abstratas que visam, de alguma forma, a representar alguns aspectos de uma determinada realidade - fato ou coisa (BUNGE, 1974). O poder de representação é a chave: segundo Armatte \& Dalmedico (2004, p. 294), um modelo não tem tanto valor em si mesmo, senão naquilo que ele faz e para aquilo que ele serve. Parece que mais importante do que encontrar uma única e precisa definição para a polissêmica palavra "modelo" é procurar por sua funcionalidade. E no que consiste, em especial, essa funcionalidade? Bunge (1974) afir-

\footnotetext{
2 O conceito de "objeto-modelo didático" surge na fusão entre a epistemologia dos modelos de Mário Bunge e a didática da ciência; são modelos de modelos científicos (ADURIZ; MORALES, 2002) levados à sala de aula por um processo de transposição didática. Para um maior aprofundamento, além de Bunge (1974) ver, por exemplo, Silva, 2011. Neste artigo, a expressão "modelos didáticos" equivale a "objetos-modelo didáticos".
} 
ma que os modelos funcionam como "pontes" de ligação entre as teorias e a realidade, operando algumas vezes como instrumentos de validação empírica de uma teoria, e em outras vezes dando origem a novos objetos-modelo e a novas teorias.

Ainda, segundo Bunge, os modelos nas Ciências podem ser do tipo caixa preta; isto é, a entrada e a saída de fatos, dados ou coisas são analisadas, não importando o que ocorre dentro da caixa. A uma determinada entrada na caixa preta 'realidade' corresponderá uma 'saída', análoga àquela que obteríamos se a mesma entrada fosse aplicada à caixa preta 'modelo'. A cinemática e a óptica geométrica seriam exemplos de modelos do tipo caixa - preta. Já a óptica física corresponde a um modelo no qual a caixa preta é, pelo menos em parte, aberta (BRANDÃO; ARAÚJO; VEIT, 2008, 2011). Os modelos, do tipo caixa preta ou não, subscrevem-se, via de regra, a um modelo teórico, o qual é, segundo Bunge (1974), expresso, em geral, em uma forma matemática. Por sua vez, uma cadeia de modelos teóricos pode compor o quadro de uma teoria geral.

Os objetos-modelo didáticos em geral são, por óbvio, modelos para ensinar e para aprender. No caso do movimento da Terra em torno do Sol, o desafio foi o de conceber e realizar modelos didáticos consistentes com os diversos modelos teóricos envolvidos, dentre os quais se destacam a teoria da gravitação universal de Newton e a conservação do momento angular. Esses modelos teóricos se inserem em uma teoria geral, que é a Mecânica Clássica (BUNGE, 1974). Será necessário, entretanto, operar dentro de certos limites; a delimitação das fronteiras de um determinado objeto-modelo didático é um dos pontos altos de seu uso no ambiente escolar.

Mas, por que conceber, fabricar e utilizar modelos num contexto de ensino de astronomia? Entre as diversas respostas possíveis, todas bastante plausíveis e defensáveis, priorizamos, aqui, a que diz respeito às concepções que os alunos trazem para dentro do ambiente escolar. De fato, esse é o grande princípio da psicologia escolar: "descubra o que [o aprendiz] sabe e baseie nisso os seus ensinamentos" (AUSUBEL; NOVAK; HANESSIAN, 1980, texto em destaque, antes do prefácio). "Descubra o que o aprendiz sabe": isto tem sido feito quase à exaustão, no que diz respeito às concepções Terra-Sol (um exemplo recente é o trabalho bastante completo de LANGHI, 2011), mas esse conhecimento produzido pela comunidade de pesquisadores em Educação e, nesse caso, em Educação em Astronomia, tem ficado predominantemente restrito a essa comunidade. Já a segunda parte do princípio - "[...] e baseie nisso seus ensinamentos" - talvez não tenha merecido uma atenção proporcional: 
[...] reconhecer a existência das concepções alternativas em Astronomia não garantiu uma mudança efetiva quanto à inserção deste tema na educação básica e na formação de professores, mesmo com todo o montante de produção científica a respeito desde o período do movimento das concepções alternativas: os professores e alunos, em geral, continuam com suas concepções espontâneas básicas em Astronomia (LANGHI, 2011, p. 391).

Como construir, então, as condições para que esses ensinamentos se transformem, de fato, em aprendizagens? Não há, é claro, uma resposta única a essa questão. As condições que apresentamos aqui (colocadas em ação por um dos autores, junto a estudantes do Ensino Fundamental) se revelaram promissoras (SILVA, 2011). A tentativa de atender a essas condições se dará, como dissemos acima, através da concepção e exploração de modelos didáticos. Mais especificamente, preocupar-nos-emos, aqui, com os chamados 'objetos-modelo' (ou modelos conceituais) que, revestindo-se das características mencionadas acima, são acrescidos de uma funcionalidade própria para uso no campo do ensino-aprendizagem, em especial, na física e astronomia (mas não só nelas: a geografia, a arquitetura e a agronomia são campos do conhecimento nos quais esse modelo teria grande utilidade). Essa funcionalidade é premeditada de tal sorte que o conceito que se quer destacar (por exemplo, a invariância da orientação do eixo de rotação da Terra) apareça explicitamente como uma propriedade funcional do modelo. Com isso em mente, descreveremos a seguir um objeto-modelo didático, no qual as posições que o Sol assume em relação ao fundo de estrelas ao longo do ano - de uma perspectiva geocêntrica ${ }^{3}$ - são materializadas em uma projeção cilíndrica, que pode girar, reconstituindo, assim, alguns dos efeitos do movimento diurno de rotação da Terra em torno de seu eixo.

Esse objeto-modelo didático é, entretanto, o 'elo final' do que chamaremos livremente de 'cadeia de objetos-modelo didáticos', cujos elementos podem levar a uma compreensão conceitual efetiva do movimento da Terra ao redor do Sol, às estações do ano, e, por fim, à posição aparente do Sol contra o fundo de estrelas. Finalmente, a ideia de 'cadeia de modelos' é consolidada por meio de um diagrama, apresentado mais adiante neste trabalho. Discorreremos com algum detalhe sobre todos os elementos dessa cadeia e as principais junções entre eles.

\footnotetext{
${ }^{3}$ Ao longo do texto, expressões do tipo "o movimento do Sol em relação ao fundo de estrelas" refletem, é claro, o movimento aparente do Sol, tal como é visto quando observado da Terra.
} 


\section{Modelos do tipo 'caixa preta'}

Onde o Sol está no dia 21 de cada mês ${ }^{4}$ ? Bohr teria dito, certa vez, que só podemos enunciar claramente uma pergunta depois de conhecer a resposta. Esse é o caso aqui: a resposta a essa pergunta - os especialistas em astronomia sabem disso - trará o que o aluno quer saber, e muito mais. Atenhamo-nos a um primeiro nível de resposta: ele poderá ser encontrado no programa livre "Stellarium", ou outra fonte similar disponível; a resposta, sob forma gráfica, pode ser estampada em um 'mapa' (parcial, bem entendido) das estrelas no céu.

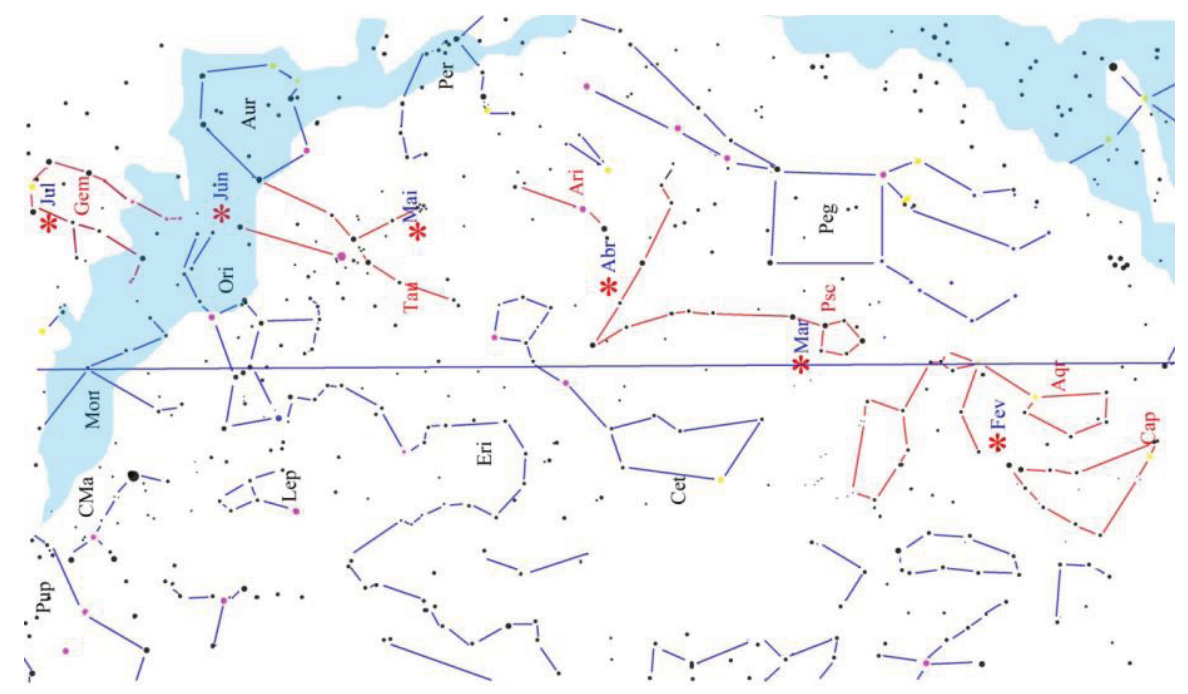

Fig. 1-a-Posições do Sol (representado por um asterisco vermelho) contra o fundo de estrelas, nos dias 21 dos meses de fevereiro a julho. A linha reta horizontal central dá a posição do equador celeste; as constelações representadas em vermelho são as chamadas constelações do zodíaco, aquelas pelas quais o Sol 'passa', ao longo do ano. As abreviaturas são feitas em relação aos nomes grafados em latim; por exemplo, 'Cet' refere-se à constelação da Baleia, 'Cetus'.

\footnotetext{
${ }^{4}$ Por volta de 21 de março e de 21 de setembro, o Sol está posicionado, respectivamente, nos dois pontos de cruzamento imaginário do círculo do equador celeste com o plano da eclíptica. Por essa razão, foi escolhido o dia 21 de cada mês para representar no modelo a posição do Sol no céu.
} 


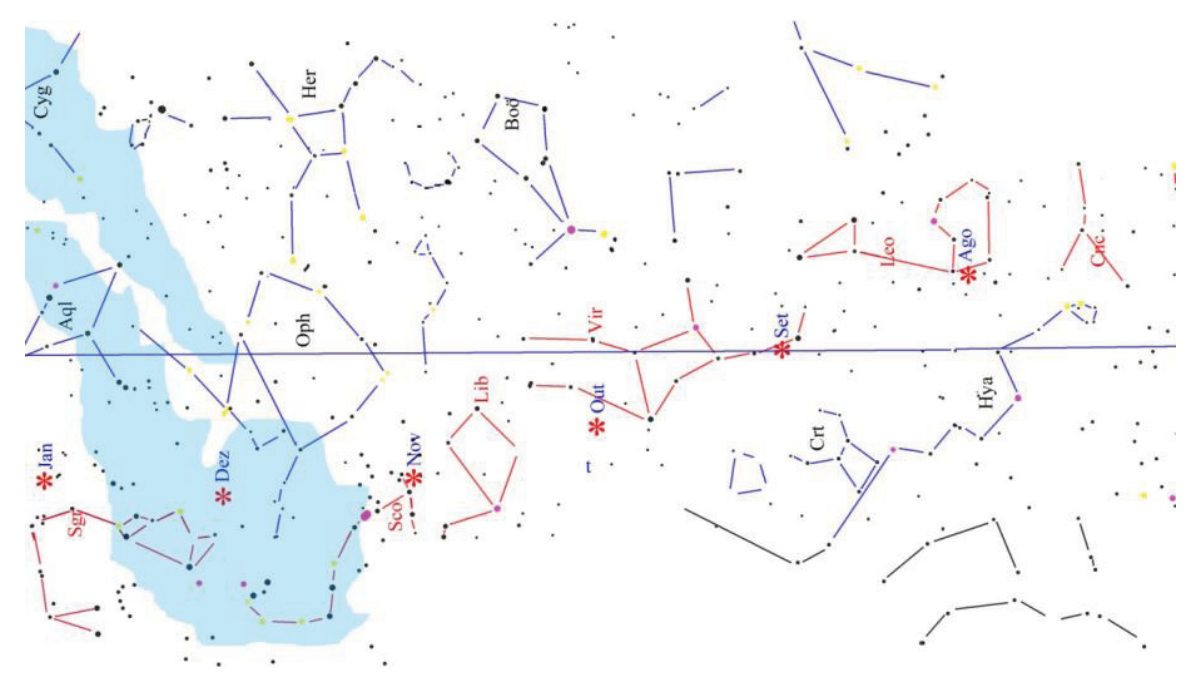

Fig. 1-b - Idem, para os meses de agosto a janeiro. (Mapa construído a partir de dados retirados do encarte central do periódico Astronomy, de Setembro de 2011, e do programa livre de astronomia Stellarium). As 'manchas' azuladas representam de forma aproximada, nas duas figuras, a Via Láctea.

Um desses mapas aparece na Fig. 1; trata-se de uma projeção de parte da 'abóbada celeste'. É uma 'carta celeste' de uma parte do céu, acrescida das posições do Sol no dia 21 de cada mês do ano, indicadas com asteriscos nas Fig. 1-a e 1-b. Dentro da base teórica aqui proposta, uma carta (um mapa) pode ser considerada um modelo, uma representação de um território, ou melhor, a representação de alguns dos lugares 'a que se pode chegar', ou visitar, neste território, que, nesse caso, é a abóbada celeste, acrescida do Sol. É importante lembrar que a abóbada celeste como um todo parece, devido à rotação da Terra, mover-se no céu; entretanto, as posições das estrelas umas em relação às outras se mantêm fixas, pelo menos na escala de tempo de muitas vidas humanas.

Esse modelo, como todos os mapas, em geral, é uma 'caixa preta', na acepção de Bunge. Ele 'funciona' dando respostas corretas a um grande número de perguntas. Onde está o Sol, em determinada época do ano? Esse é um exemplo de perguntas que são respondidas de maneira bastante precisa pela carta celeste apresentada acima. Contudo, a carta celeste não nos diz, por exemplo, por que o Sol parece estar em diferentes lugares na abóbada celeste ao longo do ano. 


\section{IV. "Abrindo a caixa preta" - 1}

Podemos tornar esse mapa um pouco menos 'caixa preta'. Para isso, é possível lhe dar uma forma mais próxima à da abóbada celeste, e dotá-lo de movimento. Abra a versão digital deste artigo na internet, e selecione a Fig. 1-a: ela poderá ser, então, copiada e colada em um arquivo de processador de texto (Open Office, Word, ou outro). Depois, poderá ser ampliada até o tamanho desejado (faça isso com a tecla shift pressionada, para não alterar as proporções). Faça o mesmo com a Fig. 1-b; amplie-a na mesma proporção da Fig. 1-a e imprima-as em uma transparência ${ }^{5}$. O passo seguinte é confeccionar um cilindro, unindo as faixas (a faixa da Fig. 1-a com a da Fig. 1-b). Corte, em seguida, um disco de madeira (ou papelão espesso, ou outro material) que possua o mesmo diâmetro do cilindro, fure o centro deste como um orifício pelo qual possa ser passado livremente um parafuso, e faça a montagem com fita adesiva dupla face. Veja o cilindro pronto nas Fig. $2,3,4$ e 5 .

Digamos que a latitude do local seja de $30^{\circ}$. Então, o cilindro deverá ser montado como na Fig. 2; note o ângulo de $30^{\circ}$ correspondente à latitude escolhida, e a direção norte-sul do local. Já o plano que contém o disco branco (aqui, ele foi feito com um $\mathrm{CD}$ revestido de papel branco), é o plano do horizonte do observador. O eixo do cilindro é paralelo ao eixo de rotação da Terra; note que o plano que contém o disco de madeira no qual foi fixada a faixa é paralelo ao plano que contém a linha do equador terrestre.

Gire o cilindro no sentido anti-horário, olhando-o pela extremidade oposta à sua base, em torno de seu eixo: você terá o movimento aparente diário do céu, do ponto de vista do observador situado no centro do disco, que representa aqui o plano do horizonte. O que era apenas um mapa, agora é um objeto mais complexo, que além de continuar sendo um mapa, captura características adicionais. A forma aproximada de parte da abóbada celeste, esférica, é projetada em um cilindro. E mais, o movimento aparente do céu passa a ser objeto de modelagem. As perguntas surgem rapidamente. Quando é dia e quando é noite? A resposta a essa pergunta de um aluno, estruturada em termos do que o modelo pode fornecer, inicia com a escolha arbitrária de um mês do ano; a posição do Sol na faixa da Fig. 1, que lhe

5 As impressoras do tipo jato de tinta, bastante populares, produzem cópias em transparência coloridas adequadas aos propósitos deste trabalho. 
corresponde é em seguida localizada. Em linhas gerais ${ }^{6}$ : quando o Sol está acima do horizonte (o plano definido pelo disco branco, plano do horizonte local), é dia. Quando ele está abaixo, é noite.

Exploremos mais este, que é, de fato, um "miniplanetário"7: O céu de dezembro à meia-noite, por exemplo, é diferente do céu de junho, também à meianoite. A Fig. 3 mostra o Sol de dezembro, na região entre a constelação de Sagitário e a de Escorpião. Como dito acima, a faixa 'gira' em sentido anti-horário, e, assim, 'vemos' o Sol se pondo, ou seja, ele 'desce' de modo a ficar abaixo do plano do horizonte, representado na foto por um disco (na versão do modelo que será descrita mais adiante, o disco que representa o plano do horizonte do observador é transparente e de borda preta, para melhor visualização). Nas condições representadas na Fig. 2, o observador (que se imaginará sempre no centro do disco que representa o plano do horizonte) ainda não veria as estrelas do céu, já que ainda é dia, e a luz do Sol ofusca o brilho das estrelas ${ }^{8}$. Logo após o pôr do sol, assim que o céu estiver suficientemente escuro, as estrelas surgirão, aproximadamente, nas posições representadas no cilindro móvel.

A linha vermelha mais espessa que aparece na Fig. 3 está pintada em um anel transparente que encaixa de forma justa na parte interna do cilindro; essa linha está dividida em vinte e quatro partes iguais, ou seja, vinte e quatro horas. Esse anel, que pode ser deslocado ao longo do cilindro, desempenha duas funções: na primeira, a linha nele impressa pode ser superposta à posição do Sol contra o fundo de estrelas, no mês escolhido para a observação, dezembro no nosso exemplo. $\mathrm{O}$ fato de o anel ser móvel permite justamente que a linha seja posicionada sobre qualquer uma das doze posições do Sol (no dia 21 de cada mês) representadas no

\footnotetext{
${ }^{6}$ Não são, por exemplo, considerados os efeitos da dispersão da luz na atmosfera. Quando o Sol transpõe exatamente a linha do horizonte, pondo-se, a luminosidade ainda perdura por algum tempo, em grande parte pelo efeito dessa dispersão. Se não existisse atmosfera, a transição dia-noite seria abrupta.

${ }^{7}$ Cabe mencionar, aqui, o excelente "planetário de pobre", criado por Rodolpho Caniato. Ver, por exemplo,

$<$ http://www.cienciamao.usp.br/tudo/exibir.php?midia=epc\&cod=_planetariodepobre $>$. Entretanto, não é possível extrair por completo desse planetário a resposta desejada à pergunta que abre este trabalho, assim como não é possível fazê-lo - por hora - com o modelo aqui proposto.

8 O programa informático Stellarium possui a função "atmosfera'; clicando-a, é possível "eliminá-la" e, assim, as estrelas aparecerão "em pleno dia". Poderemos, então, "ver" onde o Sol se situa em relação ao fundo de estrelas.
} 
cilindro. Essa linha materializa então o movimento diurno (aparente) do Sol no céu, tal como visto por um observador na Terra. Note que o cilindro gira (juntamente com as estrelas nele representadas) praticamente junto com o Sol, se for considerado um intervalo de tempo da ordem de dias; intervalo esse que é pequeno quando comparado com o intervalo de um ano. Se o intervalo de tempo for maior, digamos, um mês, o Sol se movimentará significativamente também em relação ao fundo de estrelas representado na faixa. Mais adiante, neste artigo, é proposto outro modelo que dá conta desse movimento do Sol contra o fundo de estrelas.

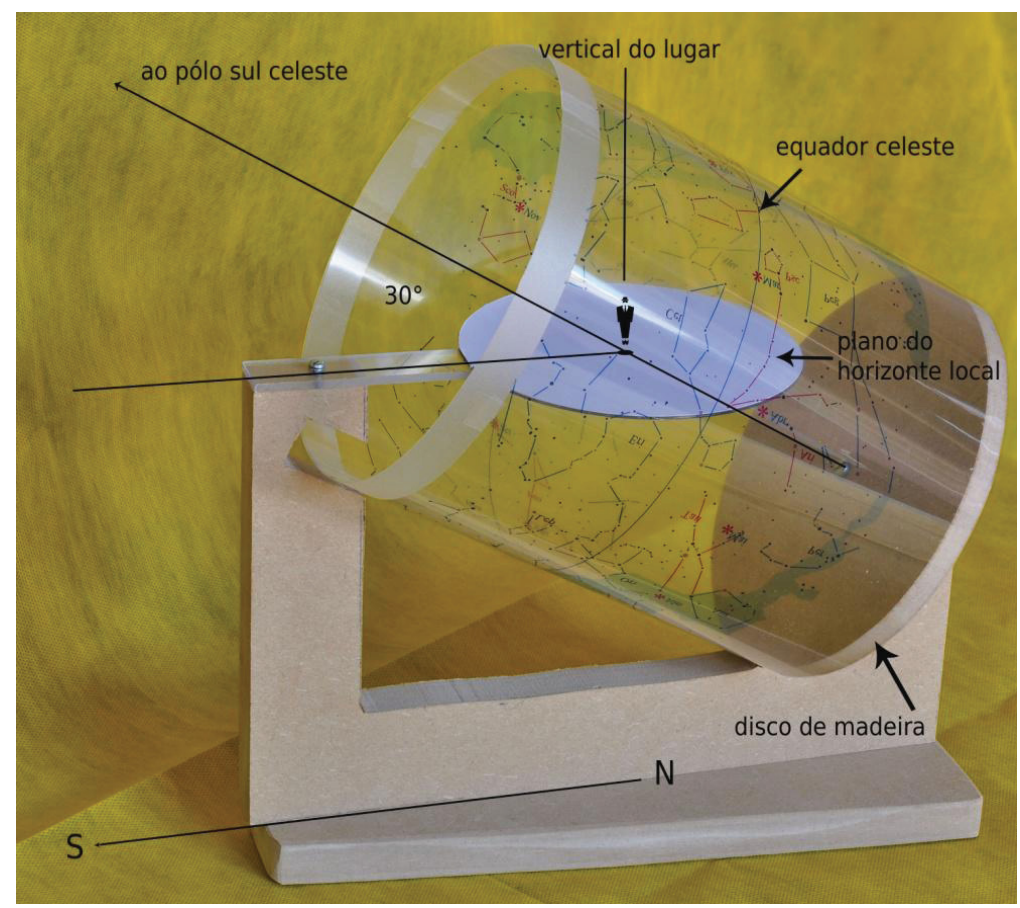

Fig. 2 - Um cilindro montado com as faixas da Fig. 1, para uma latitude de $30^{\circ}$, no hemisfério Sul. Para simular o movimento aparente do céu (e do Sol), gire o cilindro no sentido anti-horário (olhando-o pelo lado oposto à base de madeira), em torno de seu eixo. Veja também a Fig. 3. O disco branco representa o plano do horizonte; o observador imaginar-se-á sempre no centro deste disco. $O$ centro do disco branco (o horizonte do observador) deve estar contido no plano que contém o círculo do equador celeste, no centro deste. 
Na segunda função, as graduações na linha permitem estimar durante quantas horas o Sol ficará acima do horizonte, configurando, assim, a duração do dia claro 9 para o mês escolhido e para a latitude para a qual o modelo foi construído (mais adiante descreveremos em detalhe a construção desse mesmo modelo, porém acrescido da possibilidade de ajuste para qualquer latitude, de $0^{\circ}$ a $90^{\circ}$ para o hemisfério Sul). As estimativas da trajetória do Sol nos diferentes meses do ano, bem como a duração em horas do dia claro para qualquer latitude, podem ser feitas com o modelo do movimento aparente do Sol, tal como descrito por Silva, Catelli e Giovanini (2010). O modelo descrito aqui é uma evolução do modelo referido acima no seguinte aspecto: o cilindro pode girar, e então as estrelas, 'fixas' na abóbada celeste ${ }^{10}$, podem ser representadas. Com isso, esse modelo, além de prever o movimento anual do Sol (função que o modelo anterior desempenhava), também mostra a posição de uma grande parte das estrelas no céu, transformandose, assim, como dizíamos antes, em um verdadeiro miniplanetário.

Antes de prosseguir, continuemos um pouco mais nossa exploração. $\mathrm{Na}$ Fig. 3 pode-se ver o Sol (próximo a 21 de dezembro) se pondo; as constelações de Sagitário e Escorpião estão próximas a ele. Veja-as com mais clareza na faixa da Fig. 1-b; procure por 'Sag' - Sagitário, e por 'Sco', Escorpião, abreviaturas dos nomes latinos das constelações, que é como os astrônomos habitualmente as designam. Veja também, na faixa, a posição do Sol em dezembro. Os nomes das constelações e as demais legendas foram impressos de modo a aparecerem de forma não invertida na parte interna da faixa, tal como seriam vistos por um observador no centro do disco contido pelo plano do horizonte. Pois bem, enquanto essas constelações (Sagitário e Escorpião) se movem para baixo do plano do horizonte no lado do oeste, Orion (a constelação das Três Marias) sobe ${ }^{11}$, no lado diametralmente oposto - leste - e poderá ser vista no céu, não muito acima do horizonte, assim que escurece (Fig. 3). É por isso que Órion, para diversas culturas do hemisfério Sul, é a constelação que anuncia o verão.

Na Fig. 4 apresentamos mais dois modelos 'fixos': um deles construído para um observador no polo Sul, e o outro, para observadores posicionados na

\footnotetext{
${ }^{9}$ A duração do dia claro nas diversas épocas do ano está relacionada às estações; não abordaremos esse assunto aqui.

${ }^{10}$ Nesse modelo, trata-se de uma projeção cilíndrica de uma parte, significativa, mas não completa, da abóbada celeste.

11

As expressões "para baixo" e "sobe" fazem sentido no referencial do observador, no centro do disco que representa o plano do horizonte local.
} 
linha do equador. É claro que modelos similares poderão ser construídos para qualquer latitude, bastando, para isso, adequar a construção de modo que o ângulo (veja o ângulo de $30^{\circ}$ representado na Fig. 2) corresponda ao da latitude escolhida. É necessário um cuidado adicional: o centro do disco que representa o plano do horizonte do observador deve coincidir com o centro do círculo do equador celeste (nas Fig. 4-a e 4-b, e na Fig. 5-a, o equador celeste é indicado através de uma seta).

A seguir, descreveremos uma versão ajustável do modelo, que pode ser posicionada na latitude desejada, no hemisfério Sul.

Na Fig. 5-a é apresentada uma versão do modelo que pode ser ajustada para qualquer latitude, entre $0^{\circ}$ e $90^{\circ}$, ao Sul (as latitudes vão de $0^{\circ}$ a $-90^{\circ}$, do equador terrestre ao polo Sul, respectivamente). Na Fig. 5-b são apresentados, separadamente, o disco que representa o plano do horizonte e seu suporte, a base e o dispositivo de regulagem do ângulo da latitude. $\mathrm{O}$ ajuste desse ângulo é feito por meio de um parafuso (indicado por uma seta na Fig. 5-b, à esquerda), o qual permite fixar a inclinação do eixo do cilindro no ângulo desejado; à direita aparece o cilindro, idêntico aos cilindros anteriores. $\mathrm{O}$ material empregado para a estrutura dessa construção foi acrílico. Toda a montagem poderia ser feita, por exemplo, em madeira, sem nenhum inconveniente maior. Esse dispositivo é, de fato, um tanto mais complexo, do ponto de vista de sua construção, mas apresenta a vantagem evidente de poder ser posicionado na latitude desejada, o que permite 'viajar' livremente para qualquer local do hemisfério sul ${ }^{12}$.

\section{V. "Abrindo a caixa preta" - 2}

A pergunta do nosso aluno ainda não foi respondida: o Sol 'passa' pelas três Marias? Ou, alternativamente, porque o Sol aparece, no dia 21 de cada mês, nas posições apresentadas, e não em outras? É preciso abrir ainda mais a 'caixa preta'!

\footnotetext{
${ }^{12}$ Esse modelo funciona também para o hemisfério norte, da seguinte forma: 1 - O observador deverá se posicionar no centro do disco do plano do horizonte, na parte inferior, com os pés no centro do disco e a cabeça para baixo (no referencial de quem manipula o modelo); 2 - o polo celeste norte estará no prolongamento da linha que une o observador com o parafuso da base do cilindro; 3 - o sentido de rotação do cilindro (para o observador no hemisfério norte) será anti-horário; 4 - o ajuste das latitudes é o mesmo, com a diferença que, se o ângulo ajustado for de, digamos, $30^{\circ}$, ele corresponderá a uma latitude de $-30^{\circ}$ para o observador do hemisfério sul e a uma latitude de $+30^{\circ}$ para o observador descrito aqui, posicionado no hemisfério norte.
} 


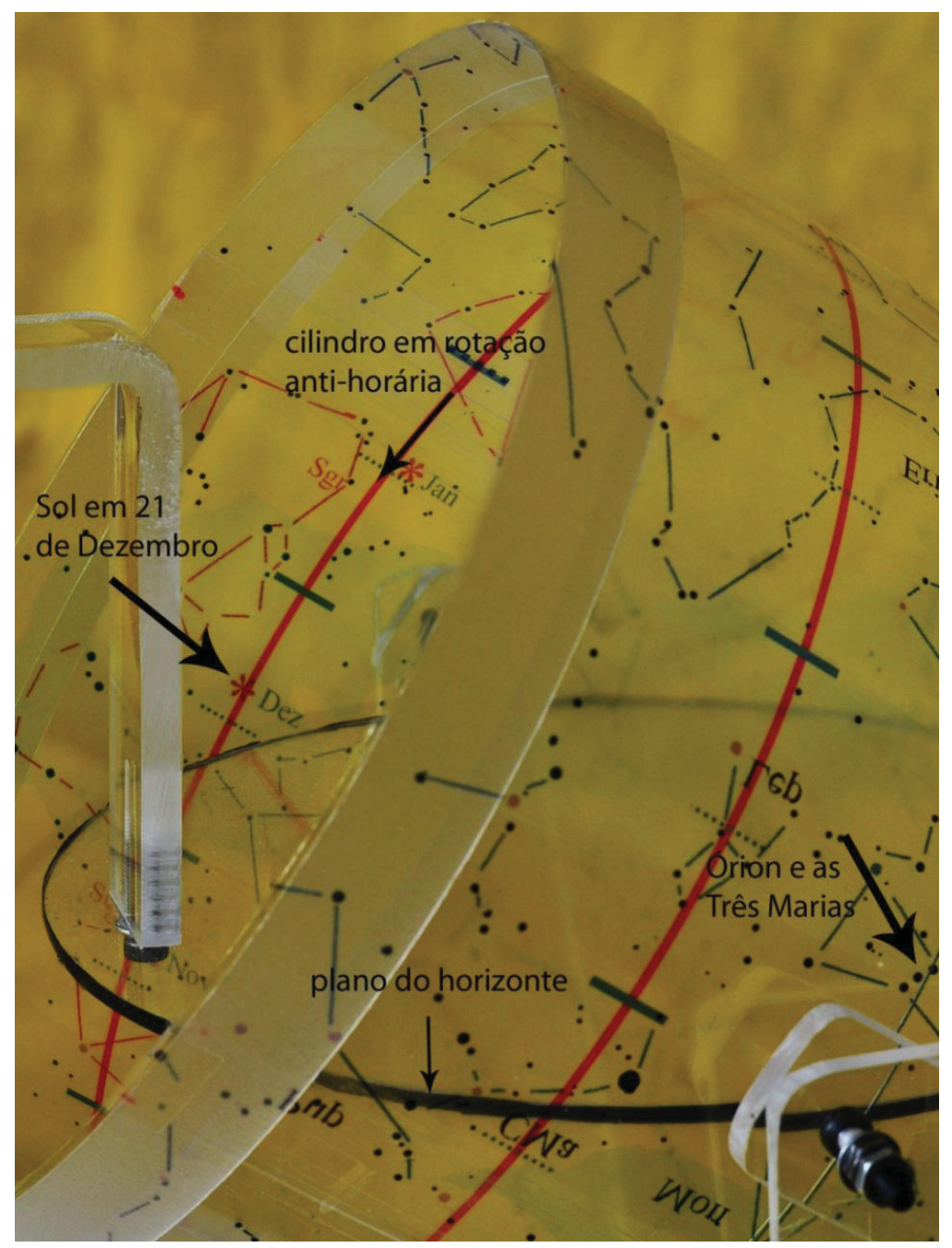

Fig. 3 - Veja a posição do Sol em 21 de Dezembro: a linha vermelha graduada foi impressa em um anel transparente; o círculo descrito por ela está dividido em vinte e quatro partes, ou vinte e quatro horas. Nessa ocasião, o Sol está entre Sagitário e Escorpião. Observe isso com mais clareza na faixa da Fig. 1-b. Como a faixa gira (tal como visto da Terra, de uma latitude de $-30^{\circ}$ ) no sentido anti-horário, o Sol se põe. Note que, simultaneamente, Órion e suas Três Marias, no lado oposto, sobem, em relação ao horizonte do observador. 
No ambiente da sala de aula, os alunos posicionam-se junto às quatro paredes da sala (eles serão as 'estrelas fixas'); no centro, coloca-se uma mesa com o 'Sol' (representado, por exemplo, por uma lâmpada de bulbo) e, entre o Sol e os alunos (as estrelas), um globo terrestre será girado em torno de seu eixo (movimento de rotação da Terra, dia e noite), ao mesmo tempo em que é transladado em círculo em volta do Sol (SILVA; CATELLI; GIOVANINI, 2010). Um aspecto deve ser destacado aqui: o assoalho, nesta configuração, representa o plano que contém a órbita da Terra em torno do Sol.
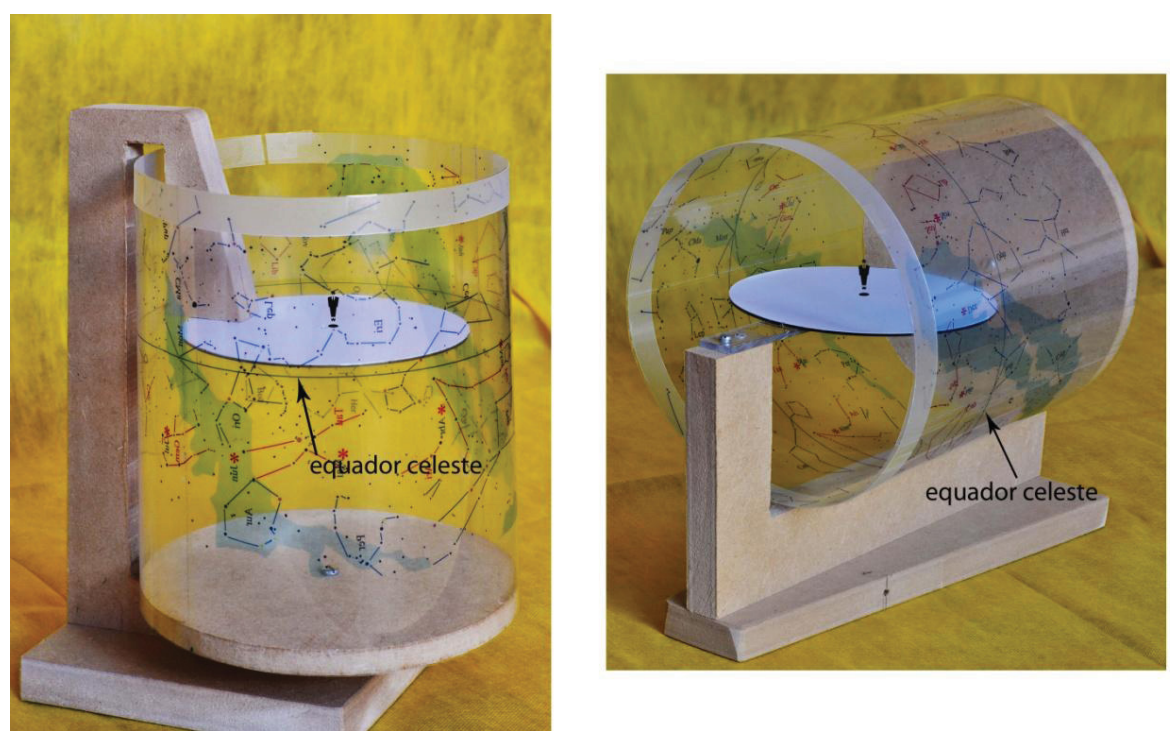

Fig. 4 - O modelo à esquerda foi construído de modo a representar o céu para um observador situado no polo sul. À direita, um modelo para observadores posicionados na linha do equador terrestre. Note que a faixa é a mesma, com o Sol sempre representado nas mesmas posições ao longo dos meses do ano. 


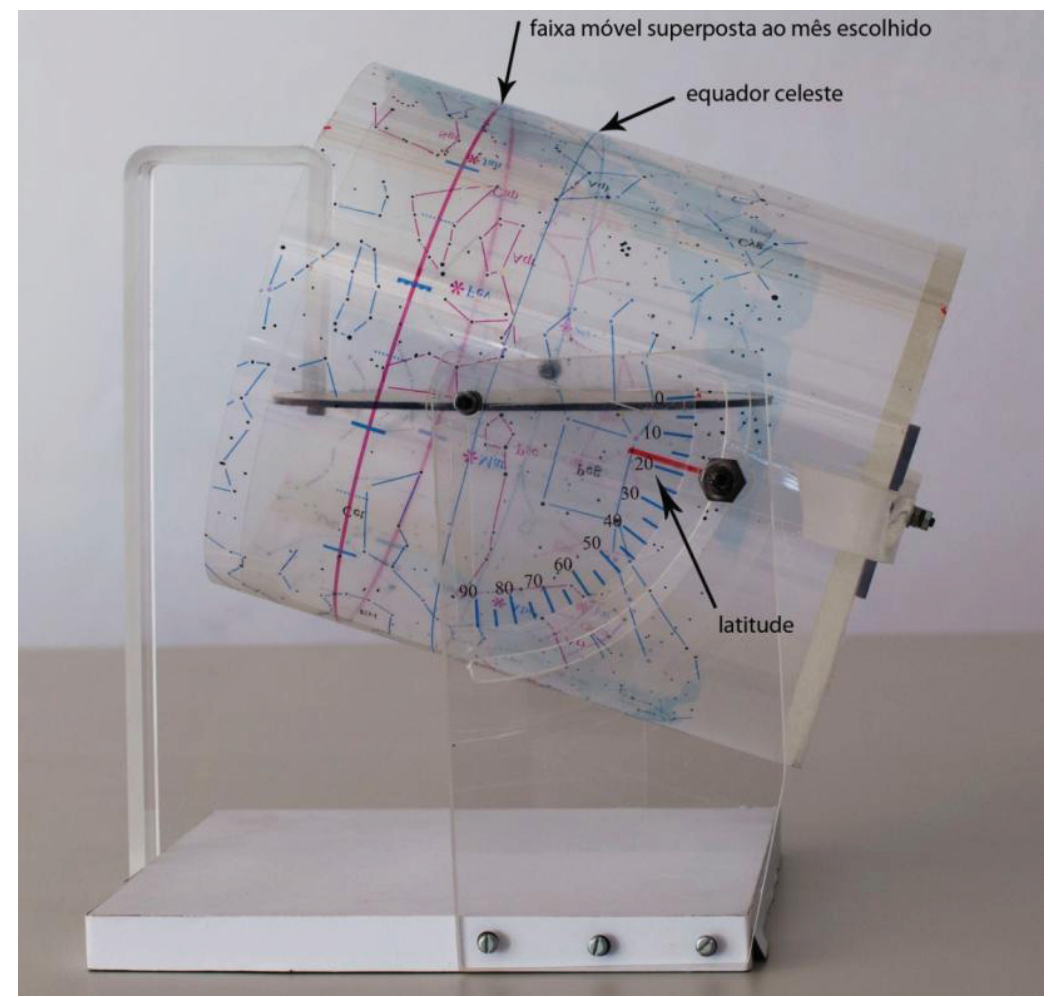

Fig. 5-a
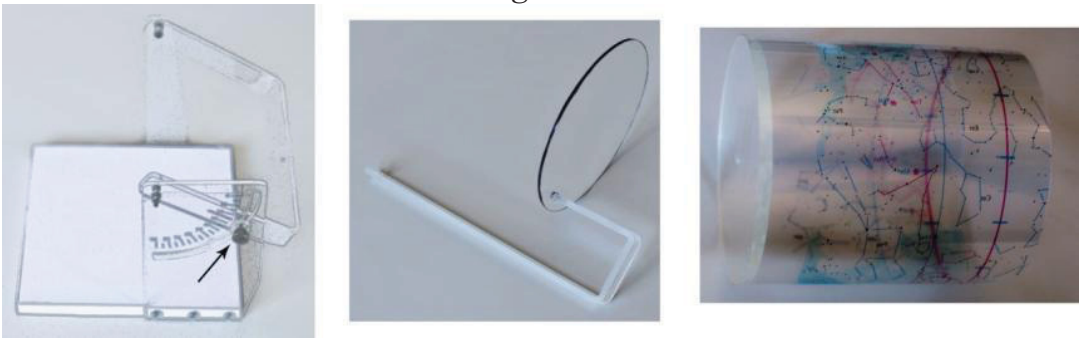

Fig. 5-b

Fig. 5-a - O sistema completo, ajustado para uma latitude de pouco menos de 20 $0^{\circ}$. Fig. 5-b-As diversas partes da montagem. À esquerda, a base, com o transferidor para ajuste da latitude, com o suporte em ' $U$ ' no centro do qual é fixado o cilindro. No centro, aparece o disco que representa o plano do horizonte, e seu suporte. A forma do suporte foi desenhada para permitir o posicionamento do cilindro na latitude de $90^{\circ}$, como na Fig. 4, à esquerda. Por fim, à direita, aparece o cilindro (idêntico aos da Fig. 4).

Cad. Bras. Ens. Fís., v. 30, n. 1: p. 131-155, abr. 2013. 


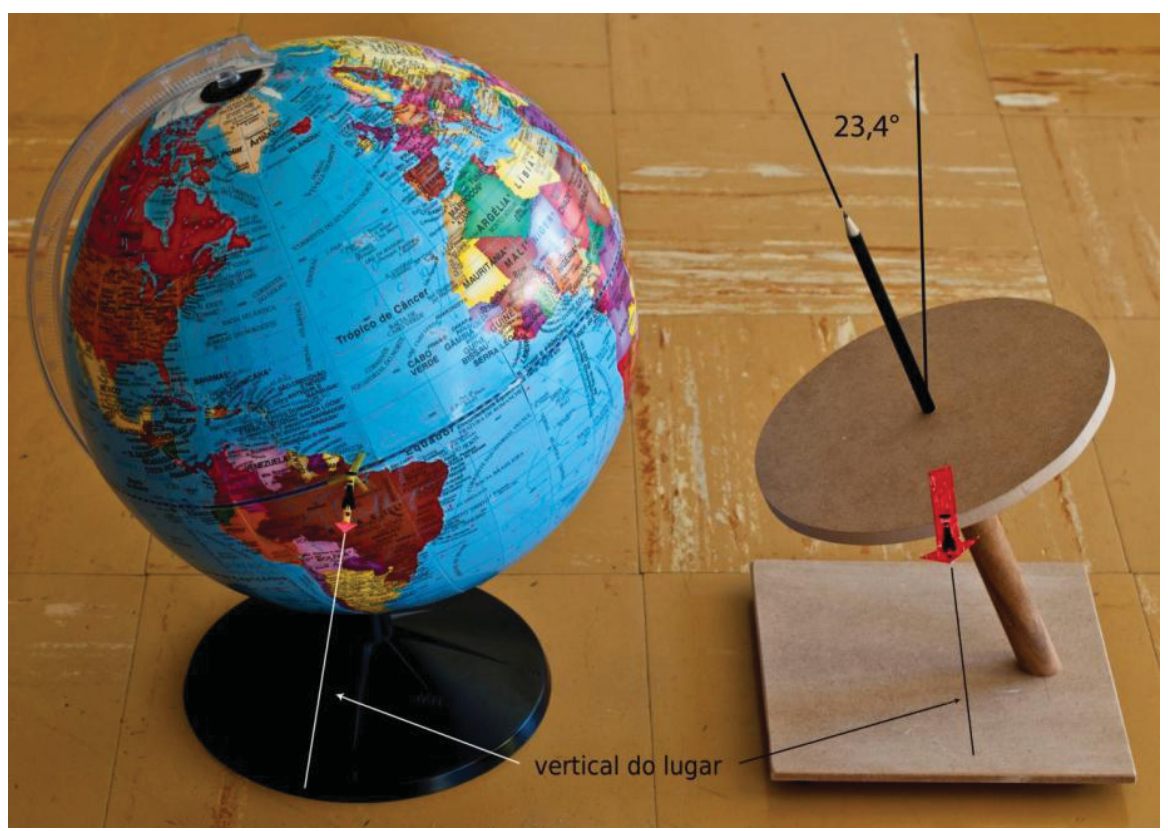

Fig. 6-Um 'modelo de um modelo': o globo terrestre (o 'modelo'), à esquerda, representa o planeta Terra; o eixo de rotação do globo está inclinado de aproximadamente $23,4^{\circ} \mathrm{em}$ relação à perpendicular ao plano do chão (que é equivalente ao plano da órbita da terra em volta do Sol). Note a seta colada sobre o globo: se ela fosse prolongada para dentro dele, ela passaria por seu centro; trata-se, portanto, da vertical do lugar. O disco (o 'modelo do modelo', à direita) cujo eixo (materializado pelo lápis), também está inclinado de $23,4^{\circ} \mathrm{em}$ relação à perpendicular ao solo, representa o plano do equador terrestre. A ponta do lápis indica o hemisfério norte. A seta (tal como a seta no globo) representa a vertical do local onde se encontra o observador, aqui também sobre a linha do equador. Tanto o globo quanto o disco, olhados de cima, giram no sentido anti-horário.

Em uma representação mais fiel, o globo faria trezentas e sessenta e cinco rotações em torno do eixo, ao mesmo tempo em que descreveria uma volta completa ao redor do Sol. Agora, vem o aspecto crítico desse segundo objeto-modelo didático: a invariância da orientação do eixo de rotação da Terra ${ }^{13}$. Quando se diz

${ }^{13}$ Uma maneira formalmente mais precisa de denotar essa invariância seria a de mencionar o vetor velocidade angular da Terra $w$, referente à rotação desta em torno de seu eixo. $\mathrm{O}$ 
que a orientação de um eixo de rotação não varia, isso significa que a direção da linha reta imaginária que passa por esse eixo não muda (essa linha passaria sempre por uma mesma estrela distante). Em um globo terrestre, a direção desse eixo de rotação seria aquela do eixo de rotação da Terra; poder-se-ia atribuir ao eixo de rotação um sentido, do polo sul para o polo norte. Além disso, esse eixo de rotação da Terra assim definido está inclinado em relação à base do globo terrestre; esse é um aspecto decisivo dos modelos aqui apresentados. Para resumir: o eixo de rotação da Terra em torno de si mesma pode ser concretizado através de uma seta, cuja direção é a desse eixo de rotação; a ponta dessa seta tem a direção do polo sul para o polo norte. Essa seta ${ }^{14}$ será representada daqui para frente pela letra $w$.

Um aspecto confunde bastante os alunos: w poderá estar em posições diferentes no espaço, e mesmo assim permanecer invariante, o que é o caso aqui ${ }^{15}$. Essa questão da invariância de w será tratada em seguida; para isso, será proposto um modelo adicional. Trata-se, na verdade, de um modelo de outro modelo: o globo terrestre. Colocaremos em evidência, nesse novo modelo, o plano do equador terrestre e o eixo de rotação da Terra: veja a Fig. 6. O passo seguinte é escolher uma posição conveniente para um observador na superfície da Terra; coloquemolo, por simplicidade, sobre o equador terrestre.

Aqui aparece um problema adicional (mais um!), também estudado exaustivamente na literatura: a vertical do lugar (LANGHI, p. 376, 2011). Convém reservar uma parte da aula para a discussão desse detalhe. Sugere-se que seja discutido, inicialmente, como é a vertical de diversos pontos, tanto no hemisfério norte quanto no sul, a partir de um globo terrestre e um pequeno boneco, uma seta, um palito, ou algo do gênero. Se esse aspecto não estiver claro, todo o resto das atividades de modelagem fica comprometido.

A seguir, quatro réplicas desse novo modelo da Terra são colocadas na sala de aula, em volta do Sol, agora representado por uma esfera de isopor; veja a Fig. 7. Agora, o observador imaginário, colocado no equador terrestre, olhará para a direção do Sol, no momento em que este estiver o mais próximo possível da

inconveniente de empregar o conceito de velocidade angular neste trabalho é a eventual restrição de seu uso por professores do Ensino Médio.

O leitor familiarizado com o assunto reconhecerá nessa seta o vetor velocidade angular.

${ }^{15}$ Um matemático diria que se trata de uma classe de equivalência, ou seja, os vetores velocidade angular da Terra nas posições correspondentes ao dia 21 de cada um dos meses do ano, por exemplo, têm a mesma direção, o mesmo sentido e o mesmo módulo. Eles são, portanto, equivalentes. 
vertical do lugar, ou seja, próximo ao meio-dia. Nas posições A e C da Fig. 7, o Sol será visto no prolongamento dessa vertical; 'atrás' dele seriam visualizadas constelações contidas no plano da órbita da Terra (as estrelas não são vistas por conta do ofuscamento devido à luz do Sol; veja também a nota de rodapé 8). No mapa celeste da Fig. 1, essa situação ocorre em março, ocasião em que o Sol será 'visto' com a constelação de Peixes 'ao fundo', e em Setembro, quando, ao fundo, aparecerá a constelação de Virgem.

Como na atividade de modelização anterior, as constelações de Peixes e de Virgem seriam materializadas por alguns dos alunos posicionados próximos às paredes, com a lâmpada (o Sol) ao centro, iluminando o globo terrestre, e este transladando em sua volta. Note que, na medida em que o globo terrestre translada em volta do Sol, o observador no equador veria, caso fosse possível "apagar" o Sol, grupos de pessoas (constelações) diferentes ao longo da linha de visada que passa por este.

Finalmente, a resposta à pergunta de nosso aluno: como se pode ver nas Fig. 7 e 8 , nas posições B e D, a vertical do observador apontará, respectivamente, 'acima' e 'abaixo' da posição do Sol do meio-dia! (Note que 'acima' e 'abaixo' se referem ao plano do assoalho da sala, ou, analogamente, ao plano da órbita TerraSol). A escolha do meio-dia é, também, apenas uma conveniência: se o Sol aparece com a constelação de, digamos, Sagitário ao fundo, isso ocorrerá durante todo o dia, já que o movimento relativo do Sol em relação ao fundo de estrelas é bastante lento, praticamente imperceptível no espaço de um dia. Então, nessas ocasiões, o observador verá os grupos de estrelas por trás do Sol acima e abaixo do plano do assoalho ou, estendendo a analogia, 'acima' e 'abaixo' do plano que contém a órbita Terra-Sol. Na carta celeste, esses eventos (B e D) corresponderão aos meses de Junho (Touro) e Dezembro (Sagitário), respectivamente. Nestas posições B e D, o Sol seria visto pelo nosso observador imaginário, situado no equador terrestre, respectivamente acima das cabeças e abaixo dos pés dos dois grupos de alunos correspondentes. Na carta celeste, quando o Sol 'está' em Touro, ele passa 'por cima' da constelação de Órion, ano após ano, para, é claro, qualquer observador em qualquer parte da Terra; isso pode ser visualizado também na Fig. 8.

Por fim, retomemos mais uma vez a questão de o Sol se mover, ao longo do ano, em relação ao fundo de estrelas. Retornemos à montagem da Fig. 7: os alunos (as 'estrelas fixas') se colocarão ao longo das paredes da sala (eles compõem assim uma parte, uma faixa da abóbada celeste). A abóbada celeste completa não seria passível de representação, já que não é viável colocar estrelas (alunos) no teto e abaixo do nível do chão da sala. Então, quando o modelo que representa a 
Terra está na posição A, um determinado grupo de alunos seria visto ao longo da linha A-S por um observador situado na borda do disco.

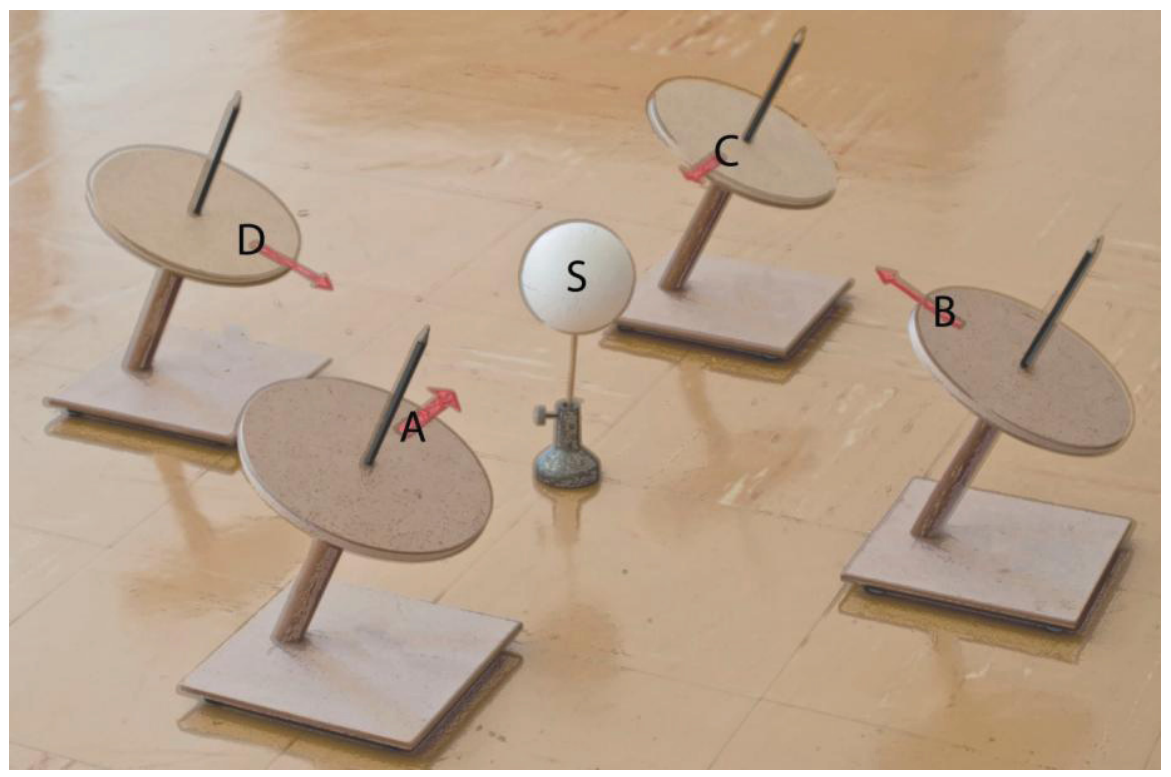

Fig. 7 - Imagine quatro réplicas do modelo da Fig. 6, à direita, colocadas no chão (chão $\rightarrow$ plano da órbita terra - Sol), no centro da sala de aula, como na foto. A esfera de isopor 'S' representa o Sol; o modelo como um todo está -é claro - fora de escala. Os alunos, colocados em volta, próximos às paredes, materializariam as 'estrelas fixas'. Um observador em A ou $C$, sobre a linha do equador, olhando na direção do Sol, na linha de visada da seta vermelha, ou seja, ao longo da vertical, próximo ao meio-dia, 'veria' os alunos (as estrelas) sobre o plano da órbita (o plano do piso da sala). Já na posição B, o Sol não será mais visto ao longo da vertical do lugar (a seta), e sim 'abaixo' desta, se considerarmos o referencial do modelo. As estrelas vistas 'ao fundo' do Sol estarão, então, 'abaixo da vertical'. Na posição D a situação é análoga, com a diferença que agora o Sol é visto 'acima' da vertical do lugar. Lembre que o lápis do modelo (ele representa w) aponta na direção do hemisfério norte do modelo da Terra. 


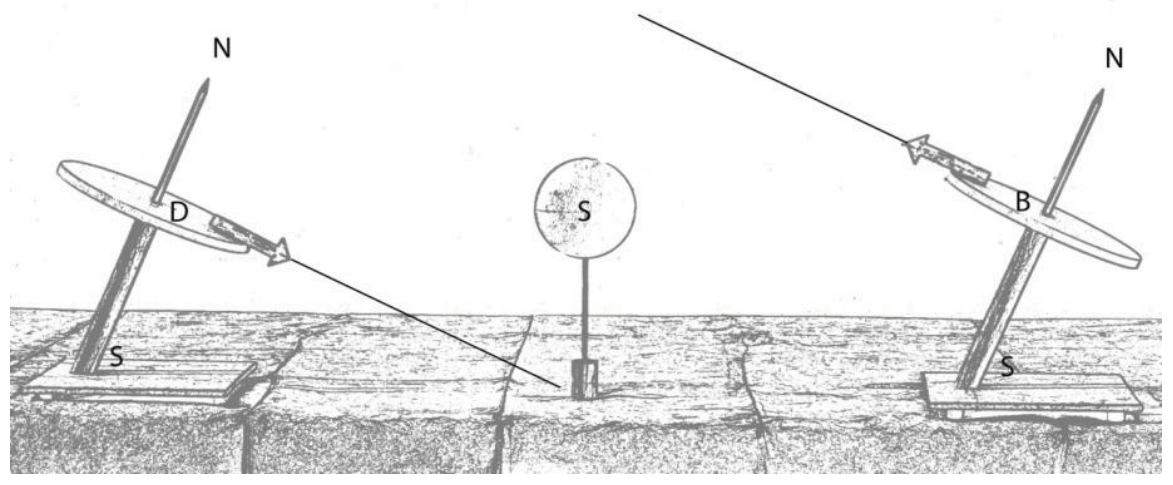

Fig. 8 - Posições D e B da Fig. 7, em representação frontal. O observador no equador da Terra, em Dezembro, na posição D à esquerda, verá o Sol entre a vertical do lugar (seta larga, no disco, na direção do zênite do lugar) e a direção do polo celeste Norte. Já para o mesmo observador, em junho, na posição $B$ à direita, o Sol é visto entre a vertical do lugar e a direção do polo celeste Sul.

Três meses depois, a Terra estará na posição B. Dessa vez, ocorrem duas coisas notáveis. A primeira: o observador, ao olhar na direção do Sol (direção B $\mathrm{S})$, verá outro grupo de alunos, colocados à frente de outra parede! Isso 'explica', então, por que, na medida em que o tempo passa, nosso observador 'vê' o Sol se 'movendo' contra o fundo de estrelas. Esse 'efeito' é resultado do fato de o observador estar sobre a Terra, em movimento de translação à volta do Sol.

A segunda coisa notável: se, na posição A, o observador via o Sol do meio-dia ao longo da linha vertical (a seta), agora, na posição B, o Sol é visto 'abaixo' da vertical (Fig. 8). A expressão 'abaixo', como de costume neste trabalho, refere-se ao plano do assoalho. Ao 'olhar' ao longo da linha B-S, o observador na borda do disco verá constelações que estão abaixo do plano do assoalho! Então, para o observador nesta posição B, o Sol não aparecerá, nunca, contra constelações que estejam próximas ao plano que contam a circunferência da eclíptica (no modelo, o plano do assoalho), ele aparecerá 'abaixo' desse plano. (Imagine-se agora como professor, tentando encaminhar junto com os alunos a resposta à questão feita, sem o recurso a algum tipo de modelo tridimensional. Difícil, não?)

A caixa preta foi aberta, pelo menos o suficiente para responder à pergunta feita. Entretanto, não é excessivo reiterar alguns aspectos, para evitar mal entendidos. O primeiro: quando uma determinada constelação está por trás do Sol (quer 
dizer, na linha de visada observador-Sol-constelação), é dia, e essa constelação não pode ser vista ${ }^{16}$, por conta do ofuscamento provocado pela luz solar. No entanto, esse fato não invalida nenhuma das previsões feitas a partir dos objetos-modelo aqui apresentados.

O segundo aspecto: o observador não precisa estar posicionado na linha do equador terrestre. Ele foi colocado lá apenas por conveniência, para simplificar um pouco as explicações e interpretações, mas ele poderia estar em qualquer lugar sobre a superfície da Terra; a linha de visada observador-Sol-constelação continuaria inalterada: note que o diâmetro da Terra é desprezível quando comparado à distância Terra-Sol ${ }^{17}$.Ou seja, o Sol seria visto contra as mesmas constelações, a partir de qualquer ponto do globo terrestre. Quanto ao 'Sol a pino', aí sim, ele só ocorrerá em latitudes menores que $23,4^{\circ}$ (aproximadamente), entre os trópicos de Câncer e de Capricórnio.

\section{Os diversos modelos, organizados para a construção da resposta}

O leitor se viu confrontado até aqui a uma verdadeira profusão de objetosmodelo didáticos, concorrendo todos eles para a construção de uma resposta. $\mathrm{Na}$ tentativa de dar alguma unidade a essa profusão, apresentamos o diagrama da Fig. 9. Alguns aspectos desse diagrama merecem destaque. As cartas, celestes ou não, os globos, os planetários, os programas informáticos e o modelo do movimento aparente do Sol foram enquadrados aqui como modelos do tipo "caixa preta". (A inclusão dos planetários como "caixas pretas" dá margem a diversas interpretações. Eles foram enquadrados nessa acepção, no contexto deste trabalho, devido ao fato que a posição do Sol deve ser ajustada de mês a mês).

A teoria geral, a Mecânica Clássica, que engloba a teoria da gravitação universal e a conservação do momento angular, é o polo para o qual tudo converge no diagrama, mais cedo ou mais tarde. É ela que polariza todos os modelos, todas as representações. Sem ela, a profusão de modelos aqui apresentados não teria unidade, não teria plano, não configuraria, enfim, um sistema, ou melhor, um subsistema, uma parte do sistema solar.

\footnotetext{
${ }^{16}$ Exceto em raras ocasiões, quando a Lua eclipsa o Sol por completo; veja também a nota 8.

${ }^{17} \mathrm{O}$ diâmetro aproximado da Terra é de $12700 \mathrm{~km}$, enquanto que a distância média TerraSol é cerca de 12000 vezes maior, algo como $150000000 \mathrm{~km}$.
} 


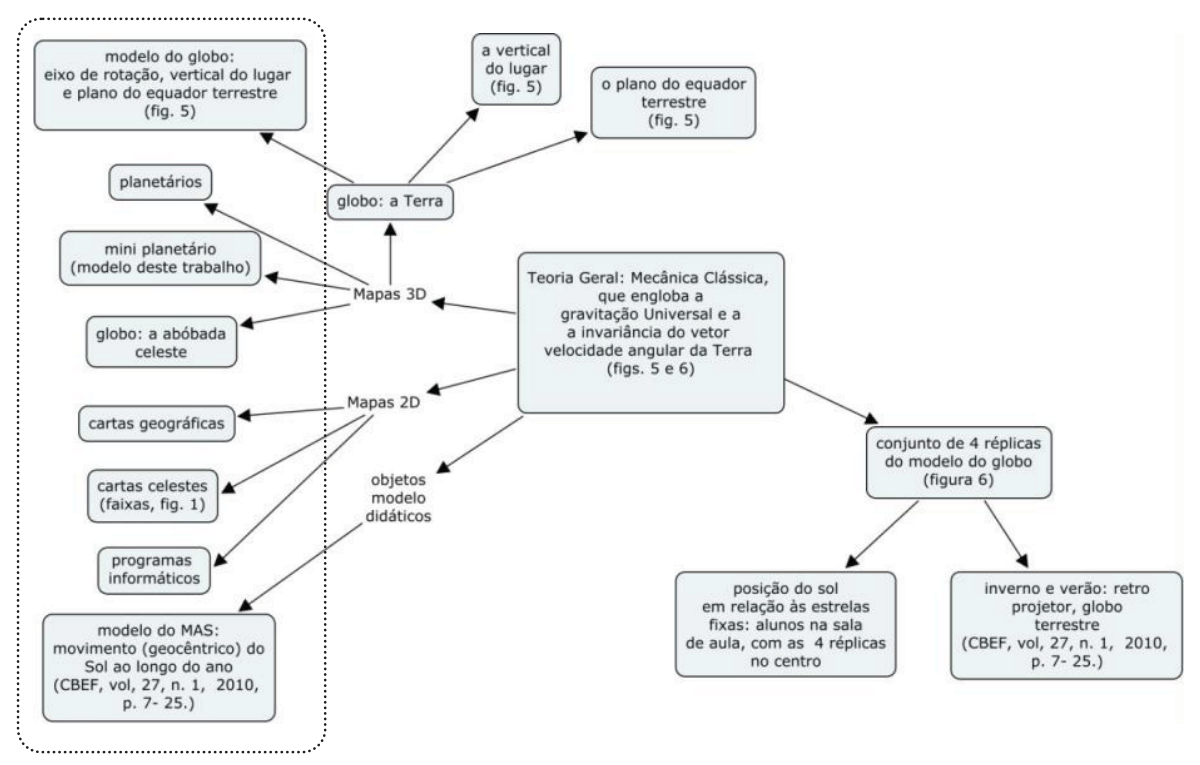

Fig. 9 - Diagrama no qual os modelos (os empregados neste trabalho, bem como alguns modelos teóricos) se relacionam entre si. Os modelos que se encontram no interior do retângulo pontilhado podem ser classificados como modelos do tipo "caixa preta". Veja o texto para maiores explicações.

\section{Conclusões}

O leitor se perguntará: por que, afinal, tanto trabalho para erigir essa sucessão de modelos? A aposta foi a de que poderíamos extrair, pelo menos em parte, o que Simon e Newel (1956) chamam de "conteúdo psicológico" de uma teoria. Explicando um pouco melhor: todo o conteúdo que pode ser extraído de uma teoria é o que esses autores chamam de "conteúdo lógico". Contudo, não é esse conteúdo que mais interessa, em um contexto de ensino e aprendizagem, bem entendido. A meta não é a de aprender por completo uma teoria, em todas as suas minúcias e em seus desdobramentos. Interessa aquela parte do conteúdo que, sendo preferencialmente estruturadora, pode ser apropriada por todo aquele que interage com a teoria: professor, ou aluno. Esse conteúdo reconstruído, reelaborado, ressignificado e recontextualizado por cada um dos usuários da teoria é o conteúdo psicológico da teoria. 
Os objetos-modelo didáticos têm todos essa pretensão: potencializar a transformação conteúdo lógico - conteúdo psicológico, em diversos níveis e com as mais diversas finalidades. Neste trabalho, foi focalizada a aprendizagem da Astronomia, e é nesse contexto que o esforço de concepção, construção e operação dos objetos-modelo didáticos encontra sentido, e é por essa razão mesma que eles são ditos "didáticos". O diagrama dos objetos-modelo didáticos e das teorias envolvidas apresentado na Fig. 9 funciona, então, como uma espécie de organizador dos principais conceitos físicos envolvidos.

Por fim, uma palavra sobre algumas das virtudes e limitações dos modelos aqui propostos. Talvez a principal virtude seja a de que os modelos aqui empregados propiciem um trânsito maior entre a perspectiva geocêntrica e a perspectiva heliocêntrica. Assim, a qualidade do conhecimento manipulado cresce: os alunos assumem, ao longo dos exercícios de modelagem, diversos pontos de vista, de acordo com a conveniência, e extraem deles informações pertinentes.

Como principal limitação, destacamos a hipótese de circularidade perfeita da órbita da Terra, contida em todos os modelos propostos aqui neste trabalho. Apesar de se constituir em uma aproximação perfeitamente aceitável para os objetivos aqui perseguidos (só queríamos responder a uma simples (!) pergunta), ela elimina, por exemplo, a possibilidade de discussão de questões horárias ligadas, por exemplo, a relógios de Sol. Para tal, seria necessário conceber e construir outros modelos, com outras características. Vamos inventá-los?

\section{Agradecimentos}

Ao CNPq e à Universidade de Caxias do Sul, pelo apoio prestado, aos revisores do CBEF pelas sugestões oferecidas.

\section{Bibliografia}

ADÚRIZ-BRAVO, A.; MORALES, L. El concepto de modelo en la enseñanza de la física - consideraciones epistemológicas, didácticas y retóricas. Caderno Catarinense de Ensino de Física, v. 19, n. 1, p. 76-88, abr. 2002.

ARMATTE, M.; DALMEDICO, A. D. Modèles et modélisations, 1950-2000: Nouvelles pratiques, nouveaux enjeux. Revue d'histoire des sciences, tome 57, n. 2, p. 243-303, 2004.

AUSUBEL, D. P.; NOVAK, J. D.; HANESIAN, H. 2. ed. Psicologia Educacional. Rio de Janeiro: Editora Interamericana, 1980. 
BOCZCO, R. Conceitos de Astronomia. São Paulo: Editora Edgard Blücher, 1984.

BRANDÃO, R. V.; ARAÚJO, I. S.; VEIT, E. A. A modelagem científica vista como um campo conceitual. Caderno Brasileiro de Ensino de Física, v. 28, n. 3, p. $507-545,2011$.

BRANDÃO, R. V.; ARAÚJO, I. S.; VEIT, E. A. A modelagem científica dos fenômenos físicos e o ensino de Física. A Física na Escola, v. 9, n. 1, p. 10-14, 2008.

BUNGE, M. Teoria e Realidade. Coleção Debates. Tradução: Gita K. Guinsburg. São Paulo: Editora Perspectiva, 1974.

CANALlE, J. B. G. O sistema Solar numa representação teatral. Caderno Catarinense de Ensino de Física, v. 11, n. 1, p. 27-32, abr. 1994.

EICHER, D. (Ed.). Encarte central. Astronomy. Set. 2011.

FRENCH, S. Ciência: Conceitos-chave em filosofia. Tradução: André Klaudat. Porto Alegre: Artmed, 2009.

LANGHI, R. Educação em Astronomia: da revisão bibliográfica sobre concepções alternativas à necessidade de uma ação nacional. Caderno Brasileiro de Ensino de Física, v. 28, n. 2, p. 373-399, 2011.

LE MOIGNe, J-L. Qu'est-ce qu'un Modèle? Confrontations Psychiatriques, número especial consagrado aos modelos, 1987. Disponível em: $<$ http://www.mcxapc.org/docs/ateliers/lemoign2.pdf $>$. Acesso em: Jun. 2010.

MACHADO, J.; VIEIRA, K. S. Modelização no ensino de Física: contribuições em uma perspectiva bungeana. In: ENCONTRO DE PESQUISA EM ENSINO DE FÍSICA, XI, 2008, Curitiba. Disponível em:

$<$ http://www.sbf1.sbfisica.org.br/eventos/epef/xi/sys/resumos/T0223-1.pdf $>$. Acesso em: Nov. 2010.

MOREIRA, M. A. A Teoria de Educação de Novak e o modelo de ensino aprendizagem de Gowin. In: Teorias de Aprendizagem. São Paulo: EPU, 2011.

OLIVEIRA FILHO, K. S.; SARAIVA, M. F. O. Astronomia e Astrofísica. Porto Alegre: UFRGS, 2000. 
PIETROCOLA, M. Construção e Realidade: o realismo científico de Mário Bunge e o ensino de ciências através de modelos. Investigações em ensino de ciências, v. 4, n. 3, 1999. Disponível em: <http://www.if.ufrgs.br/ienci/>. Acesso em: Dez. 2010 .

SILVA, F. S; CATELLI, F.; GOVANNINI, O. Um modelo para o movimento anual do Sol a partir de uma perspectiva geocêntrica. Caderno Brasileiro de Ensino de Física, v. 27, n. 1, p. 7- 25, 2010.

SILVA, F. S. Objetos-modelo no ensino de Astronomia e o processo da transposição didática. 2011. Dissertação (Mestrado em Educação) - Universidade de Caxias do Sul.

SIMON, H. A.; NEWELL, A. Models: their uses and limitations. In: WHITE, L. (Org.). The states of the Social Science. Chicago: The University of Chicago Press, 1956.

\section{Programas informáticos de acesso livre}

Stellarium: stellarium.org.pt 